\title{
DIMENSI PARTISI GRAF LENGKAP
}

\author{
Vivi Ramdhani \\ Institut Agama Islam Negeri Batusangkar \\ Jalan Sudirman No. 137 Lima Kaum Batusangkar \\ Email: viviramdhani@iainbatusangkar.ac.id
}

\begin{abstract}
Resolving partition is part of graph theory. Resolving partition is needed to obtain partition dimension. So far it has not been discussed regarding resolving partition of complete graphs. For this reason, this article explains the resolving partition of a complete graph.Given a connected graph $G$ and $S$ is a subset of $V(G)$, write $S \subseteq V(G)$. Suppose there is $v \in V(G)$, then the distance between $v$ to $S$ is denoted in the form of $d(v, S)=\min \{d(v, x) \mid x \in S\}$. Then, suppose there is a partitioned set of $V(G)$, write $\Pi=\left\{S_{1}, S_{2}, \ldots, S_{k}\right\}$, then we can obtain a $v$ representation of $\Pi$ in the form of $r(v \mid \Pi)=\left(d\left(v, S_{1}\right), d\left(v, S_{2}\right), \ldots, d\left(v, S_{k}\right)\right)$. The partition set $\Pi$ is called a resolving partition if the representation of each $v \in V(G)$ with $\Pi$ is different. The minimum cardinality of the resolving $k$ partition against $V(G)$ is called the partition dimension of $G$, denoted by $\operatorname{pd}(G)$. To get the partition dimension of a complete graph, first we find the resolving partition og the graph, resolving partition $K_{n}$ orde $n$. After that, to assist in obtaining the partition dimensions of complete graph, $K_{n}$ we explained that if $G$ is is a connected graph then $p d(G) \leq \operatorname{dim}(G)+1$. Based on these steps, finally obtained that the partition dimension of the complete graph, namely $p d\left(K_{n}\right)=n$.
\end{abstract}

Keywords: Complete Graph, Partition Dimension, Resolving Partition

\section{PENDAHULUAN}

Teori graf merupakan salah satu bidang dalam matematika. Secara sederhana graf adalah sebuah diagram yang memuat titik-titik dan garis yang menghubungkan titik-titik tersebut yang dapat ditulis sebagai $G=(V, E)$, dimana $V$ adalah himpunan dari titik dan $E$ adalah himpunan dari sisi. Setiap sisi menghubungkan tepat dua titik dan setiap titik dapat memiliki banyak sisi yang menghubungkan dengan titik yang lainnya (G Chartrand \& Lesniak, 1979).

Dimensi partisi merupakan bagian dari teori graf. Topik ini sangat menarik untuk dibahas karena konsep tersebut aplikatif dalam kehidupan sehari-hari sehingga dapat diaplikasikan dalam menyelesaikan suatu masalah dalam kehidupan terutama yang terkait dengan mencari lintasan terpendek. Beberapa peneliti sebelumnya sudah menyingung mengenai dimensi partisi sebuah graf. Diantaranya, penelitian yang mengkaji tentang dimensi partisi graf (Gary Chartrand, Salehi, \&
Zhang, 2000), penelitian yang mengulas mengenai dimensi partisi graf reguler infinit (Tomescu \& Imran, 2009), serta penelitian yang juga membahas mengenai dimensi partisi graf (Javaid \& Shokat, 2008). Penelitian mengenai dimensi partisi ini terus berkembang seiring dengan perkembangan waktu yang membahas berbagai jenis graf lainnya.

Misalnya diberikan sebuah graf lengkap, sebut $K_{n}$. Himpunan titik pada setiap graf dipartisi menjadi beberapa partisi yang membentuk himpunan terurut $k$-partisi, tulis $\Pi=\left\{S_{1}, S_{2}, \ldots, S_{k}\right\}$. Akan ditentukan nilai $k$ minimum dari himpunan $k$-partisi sehingga representasi setiap titik pada masing-masing graf terhadap $\Pi$ berbeda. Tujuan dari penulisan artikel ini adalah untuk menentukan resolving partisi dan dimensi partisi dari graf lengkap $K_{n}$

Resolving partisi suatu graf ini penting untuk diketahui karena teori ini berkaitan dengan lintasan terpendek. Di sisi lain lintasan terpendek ini sangat bermanfaat untuk diaplikasikan dalam 
kehidupan sehari-hari. Misalnya seseorang hendak berangkat dari kota A menuju kota B. Ada beberapa rute yang bisa ditempuh agar sampai ke kota B. Supaya menghemat waktu orang tersebut pasti akan memilih mana lintasan yang paling pendek supaya cepat sampai ke tujuan. Analogi tersebut dapat digunakan untuk melihat manfaat dari resolving partisi dan pada akhirnya dapat ditentukan dimensi partisi dari graf yang menjadi bahasan, yaitu graf lengkap, $K_{n}$.

\section{KAJIAN PUSTAKA}

$G=(V, E)$ disebut suatu graf jika terdiri dari pasangan himpunan $(V, E)$ dengan $V$ adalah himpunan titik di graf $G$ dan $E$ adalah himpunan pasangan tak terurut dari unsur-unsur di $V$ (Chartrand, 1993). Jalan dari titik $v_{0}$ ke $v_{n}$ di $G$ adalah barisan hingga $v_{0}, e_{1}, v_{1}, e_{2}, \ldots, e_{n}, v_{n}$ dari titik-titik dan sisi-sisi di $G$ sedemikian sehingga $v_{i-1} v_{i} \in E(G)$ untuk $i=1,2, \ldots, n$. Jalan dari $v_{0}$ ke $v_{n}$ dapat ditulis dengan $v_{0} v_{n^{-}}$ jalan (G Chartrand \& Oellermann, 1993). Panjang dari jalan adalah banyaknya sisi dari barisan tersebut (G Chartrand \& Oellermann, 1993). Jalan dikatakan tertutup jika $v_{0}=v_{n}$ dan dikatakan terbuka jika $v_{0} \neq v_{n}$ (G Chartrand \& Oellermann, 1993). Suatu jalan dikatakan lintasan apabila semua titik dan sisinya berbeda. Lintasan dari $v_{0}$ ke $v_{n}$ juga dapat ditulis dengan $v_{0} v_{n}$-lintasan ( $\mathrm{G}$ Chartrand \& Oellermann, 1993). Lintasan terpendek dari $v_{0}$ ke $v_{n}$ adalah jumlah sisi minimum yang terdapat pada $v_{0} v_{n^{-}}$ lintasan (Gary Chartrand \& Zhang, 2001). Suatu graf $G$ dikatakan graf terhubung apabila untuk setiap dua titiknya terdapat lintasan (G Chartrand \& Oellermann, 1993). Jarak antara dua titik, sebut $u$ dan $v$ pada sebuah graf terhubung $G$ adalah banyaknya sisi yang terdapat pada lintasan terpendek dari kedua titik tersebut, dinotasikan dengan $d(u, v)$ (Gary Chartrand, Raines, \& Zhang, 2000). Jika sisi $e=u v$ dengan $u, v \in V(G)$ maka titik $u$ dikatakan bertetangga dengan titik $v$ dan demikian sebaliknya. Suatu graf $G$ disebut dengan sebuah graf lengkap, sebut $K_{n}$ apabila setiap dua titik di $G$ bertetangga (G Chartrand \& Oellermann, 1993). Hal ini dapat dilihat pada Gambar 1.

Berikut diberikan beberapa definisi yang akan digunakan pada bagian hasil dan pembahasan:

Definisi 1 Misalkan $G$ adalah suatu graf terhubung dan misalkan $S$ adalah sebuah subhimpunan dari $V(G)$. Selanjutnya, misalkan terdapat sebuah titik $v \in V(G)$ maka diperoleh jarak antara $v$ dan $S$ didefinisikan sebagai $d(v, S)=\min \{d(v, x) \mid x \in S\} \quad$ (Javaid \& Shokat, 2008).

Definisi 2 Misalkan $G$ adalah suatu graf terhubung dan $V(G)$ dipartisi menjadi beberapa partisi, sebut $S_{1}, S_{2}, \ldots, S_{k}$ dan misalkan $\Pi$ adalah himpunan terurut $k$-partisi, tulis $\Pi=\left\{S_{l}\right.$, $\left.S_{2}, \ldots, S_{k}\right\}$ dari $V(G)$. Selanjutnya, misalkan terdapat sebuah titik $v$ pada $G$, maka diperoleh representasi $v$ terhadap $\Pi$ dalam bentuk $r(v \mid \Pi)=\left(d\left(v, S_{1}\right), d\left(v, S_{2}\right), \ldots, d\left(v, S_{k}\right)\right)$.

Partisi $\Pi$ disebut resolving partisi jika k-vektor $r(v \mid \Pi)$ berbeda untuk setiap $v \in V(G)$ (Javaid \& Shokat, 2008).

Definisi 3 Nilai minimum $k$ dari resolving $k$ partisi terhadap $V(G)$ disebut dimensi partisi dari $G$ yang dilambangkan dengan $\operatorname{pd}(G)$ (Javaid \& Shokat, 2008).

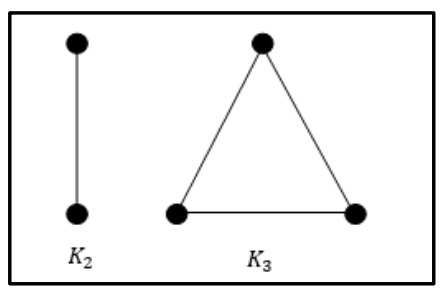

Gambar 1. Graf lengkap, $K_{2}$ dan $K_{3}$ 
Definisi 4 Himpunan $W$ disebut resolving set dari suatu graf terhubung $G$ apabila semua titik yang ada di $G$ memiliki representasi yang berbeda. Suatu resolving set yang dibangun oleh jumlah minimum titik-titik disebut resolving set minimum atau basis dari G. Sedangkan jumlah titik yang ada dalam suatu basis disebut dimensi $G$ atau $\operatorname{dim}(G)$ (Tomescu \& Imran, 2009).

\section{METODE PENELITIAN}

Dalam penelitian ini penulis menggunakan metode studi pustaka dengan membaca dan mempelajari literatur dan artikelartikel yang terkait dari penelitian-penelitian sebelumnya. Hal ini dimaksudkan untuk memperkuat teori-teori yang mendukung masalah yang akan diteliti sehingga ditemukan pembahasan dari masalah yang diungkapkan.

Dalam artikel ini dilakukan beberapa langkah untuk memperoleh dimensi partisi graf lengkap $K_{n}$ yang berorde $n$. Untuk mendapatkan dimensi partisi graf tersebut, terlebih dahulu dicari resolving partisi graf lengkap $K_{n}$. Kemudian, untuk membantu dalam memperoleh dimensi partisi graf lengkap, $K_{n}$ dijabarkan bahwa jika $G$ adalah suatu graf terhubung maka $(G) \leq \operatorname{dim}(G)+1$. Berdasarkan langkahlangkah tersebut, terakhir akan diperoleh dimensi partisi dari graf lengkap $K_{n}$.

\section{HASIL DAN PEMBAHASAN}

\section{Resolving Partisi Graf Lengkap}

Untuk membantu dalam membentuk resolving partisi dari suatu graf terhubung $G$, dapat digunakan lema berikut ini:

Lema $1 \quad G$ adalah suatu graf terhubung. Misalkan $\Pi$ adalah suatu resolving partisi dari $V(G)$ dan $u, v \in V(G)$. Jika $d(u, w)=$ $d(v, w)$ untuk setiap $w \in V(G) \backslash\{u, v\}$, maka $u$ dan $v$ termasuk pada kelas-kelas yang berbeda dari $\Pi$.

Bukti. Metode pembuktiannya dengan menggunakan kontradiksi.

Misalkan $\Pi=\left(S_{1}, S_{2}, \ldots, S_{k}\right)$ adalah himpunan terurut $k$-partisi dari $V(G)$ dengan $k$ adalah bilangan asli yang dibatasi oleh jumlah titik di $G$ dan misalkan $u, v$ adalah elemenelemen yang terdapat pada kelas $\Pi$ yang sama. Jika diketahuid $(u, w)=d(v, w)$ untuk setiap $w \in V(G) \backslash\{u, v\}$,maka akan ditunjukkan $\Pi$ bukan suatu resolving partisi dari $V(G)$.

Langkah pertama perhatikan bahwa $\Pi=$ $\left(S_{1}, S_{2}, \ldots, S_{k}\right)$ dengan $u$ dan $v$ termasuk pada kelas $\Pi$ yang sama, misalkan $S_{i}$. Jadi, dapat diperoleh bahwa $d\left(u, S_{i}\right)=d\left(v, S_{i}\right)=0$ karena jarak dari suatu titik terhadap dirinya sendiri adalah nol. Telah diketahui bahwa $d(u, w)=d(v, w)$ untuk setiap $w \in V(G)$ $\{u, v\}$, hal ini mengakibatkan $d\left(u, S_{j}\right)=$ $d\left(v, S_{j}\right)$ untuk setiap $j$ dengan $1 \leq j \neq i \leq k$. Dengan demikian, diperoleh $r(u \mid \Pi)=r(v \mid \Pi)$ untuk setiap titik di $G$. Karena terdapat representasi yang sama untuk setiap titik di $G$ maka menurut Definisi 2 diperoleh bahwa $\Pi$ bukan suatu resolving partisi dari $V(G)$.

Selanjutnya dibahas resolving partisi dari sebuah graf lengkap. Misalkan sebarang graf lengkap, $K_{n}$ yang berorde $n$ akan diperoleh beberapa bentuk resolving partisi. Sekarang perhatikan suatu graf lengkap $G=K_{n}$ dengan $V\left(K_{n}\right)=$ $\left\{v_{1}, v_{2}, \ldots, v_{n}\right\}$, dan misalkan $v_{1}, v_{2} \in V\left(K_{n}\right)$ sebarang. Karena $K_{n}$ adalah suatu graf lengkap maka untuk setiap dua titik di $K_{n}$ bertetangga. Dengan demikian, diperoleh bahwa $d\left(v_{1}, w\right)=$ $d\left(v_{2}, w\right)$ untuk setiap $w \in V\left(K_{n}\right)-\left\{v_{1}, v_{2}\right\}$.

Untuk membentuk $\Pi$ sebagai suatu resolving partisi dari $V\left(K_{n}\right)$, maka setiap titik yang ada pada $K_{n}$ harus berada pada kelas $\Pi$ yang berbeda. Oleh karena itu, $V\left(K_{n}\right)$ mesti dipartisi menjadi sebanyak n-partisi, tulis $\Pi=$ $\left\{S_{1}, S_{2}, \ldots, S_{n}\right\}$. Dengan demikian, setiap himpunan partisi yang ada pada $K_{n}$ hanya terdiri dari satu titik saja . Jadi, dari suatu $K_{n}$ hanya terdapat satu kemungkinan bentuk $k$-partisi dengan nilai $\mathrm{k}$ sebanyak orde $K_{n}$. Namun, sebenarnya dapat dibentuk beberapa resolving partisi lainnya dengan syarat setiap himpunan partisi hanya terdiri dari satu titik.. Untuk lebih jelasnya perhatikan Gambar 2. 


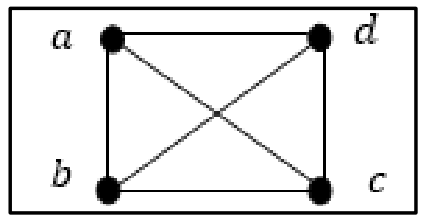

Gambar 2. Suatu graf lengkap, $K_{4}$

$K_{4}$ pada Gambar 2 adalah suatu graf lengkap yang berorde 4 . Misalkan $K_{4}$ dipartisi menjadi empat partisi dan $\Pi$ adalah himpunan terurut 4partisi, dapat ditulis $\Pi=\left\{S_{1}, S_{2}, S_{3}, S_{4}\right\}$ dimana $S_{1}=\{a\}, S_{2}=\{b\}, S_{3}=\{c\}$, dan $S_{4}=$ $\{d\}$. Adapun representasi dari setiap titik di $K_{4}$ terhadap $\Pi$ adalah sebagai berikut:

$$
\begin{aligned}
r(a \mid \Pi) & =\left(d\left(a, S_{1}\right), d\left(a, S_{2}\right), d\left(a, S_{3}\right), d\left(a, S_{4}\right)\right. \\
& =(0,1,1,1) \\
r(b \mid \Pi) & =\left(d\left(b, S_{1}\right), d\left(b, S_{2}\right), d\left(b, S_{3}\right), d\left(b, S_{4}\right)\right) \\
& =(1,0,1,1) \\
r(c \mid \Pi) & =\left(d\left(c, S_{1}\right), d\left(c, S_{2}\right), d\left(c, S_{3}\right), d\left(c, S_{4}\right)\right) \\
& =(1,1,0,1) \\
r(d \mid \Pi) & =\left(d\left(d, S_{1}\right), d\left(d, S_{2}\right), d\left(d, S_{3}\right), d\left(d, S_{4}\right)\right) \\
& =(1,1,1,0)
\end{aligned}
$$

Dengan demikian diperoleh bahwa $\Pi$ merupakan suatu resolving partisi dari $K_{4}$. karena representasi setiap titik di $K_{4}$ terhadap $\Pi$ berbeda. Sebenarnya selain dari $\Pi$, masih dapat dibuat beberapa resolving partisi dari $K_{4}$ dalam bentuk lain asalkan hanya terdapat satu titik pada setiap partisinya. Artinya, kemungkinan bentuk $k$-partisi hanya satu, yaitu 4-partisi, akan tetapi himpunan titik pada setiap partisi dapat dibuat dalam beberapa bentuk asalkan pada setiap himpunan partisi tersebut hanya terdapat satu titik saja.

\section{Dimensi partisi Graf Lengkap, $\boldsymbol{p d}\left(K_{n}\right)$}

Apabila $G$ adalah suatu graf lintasan berorde $n$ maka $G$ juga merupakan sebuah graf terhubung karena setiap dua titik di $G$ dihubungkan oleh suatu lintasan. Hal yang sama juga berlaku pada graf lengkap berorde $n$. Apabila $G$ adalah suatu graf lengkap maka $G$ juga merupakan suatu graf terhubung. Oleh karena itu, sebelum membahas dimensi partisi graf lengkap terlebih dahulu dibahas dimensi partisi graf terhubung.

Teorema 1 Jika $G$ adalah suatu graf terhubung nontrivial berorde $n$, maka $P d(G) \leq$ $\operatorname{dim}(G)+1$.

Bukti. Misalkan $W=\left\{w_{1}, w_{2}, \ldots, w_{k}\right\}$ basis dari $G$. Menurut Definisi 7 yang menyatakan bahwa dimensi dari suatu graf $G$ diperoleh dari jumlah titik yang ada pada basisnya, maka $\operatorname{dim}(G)=k$.

Selanjutnya, misalkan $V(G)$ dipartisi menjadi $(k+1)$-partisi. Perhatikan bahwa $\Pi$ adalah himpunan terurut dari $(k+1)$-partisi, $\Pi=\left\{S_{1}, S_{2}, \ldots, S_{k+1}\right\}$, dengan $S_{i}=\left\{w_{i}\right\}$ dan $S_{k+1}=V(G)-W$. Dengan demikian, diperoleh representasi $v$ terhadap $\Pi \quad r(v \mid \Pi)=$ $\left(d\left(v, w_{1}\right), d\left(v, w_{2}\right), \ldots, d\left(v, w_{k}\right), 0\right) \quad$ yang berlaku untuk setiap $v \in V(G)-W$. Perhatikan bahwa $W$ adalah suatu resolving set dari $G$, maka diperoleh representasi yang berbeda dari setiap $v \in S_{k+1}$ terhadap $W$. Hal ini mengakibatkan representasi $v \in S_{k+1}$ terhadap $\Pi$ juga berbeda. Representasi $w_{i}$ terhadap $\Pi$, tulis $r\left(w_{i} \mid \Pi\right)$, dengan $1 \leq i \leq k$, memiliki entri ke- $i$ bernilai nol. Oleh karena itu, didapatkan representasi $w_{i}$ terhadap $\Pi$, $r\left(w_{i} \mid \Pi\right)$, yang berbeda untuk $1 \leq i \leq k$. Akibatnya, didapatkan bahwa $r(v \mid \Pi) \neq$ $r\left(w_{i} \mid \Pi\right)$ untuk setiap $v \in V(G)-W$ dan $1 \leq$ $i \leq k$. Karena representasi setiap titik terhadap $\Pi$ berbeda maka berdasarkan Definisi 2 diperoleh $\Pi$ adalah suatu resolving $(k+$ 1) - partisi dari $G$. Jadi, disimpulkan bahwa $P d(G) \leq k+1=\operatorname{dim}(G)+1$.

Teorema 2 Misalkan $G$ adalah suatu graf terhubung berorde $n$, maka $p d(G)=n$ jika dan hanya jika $G=K_{n}$. 


\section{Bukti :}

Misalkan $G$ adalah suatu graf terhubung berorde $n$. Jika $G=K_{n}$ maka akan ditunjukkan bahwa $p d\left(K_{n}\right)=n$. Perhatikan bahwa $G=K_{n}$ dengan $V(G)=\left\{v_{1}, v_{2}, \ldots, v_{n}\right\}$. Ambil dua titik sebarang di $K_{n}$, misalnya titik $v_{1}$ dan titik $v_{2}$. Karena $K_{n}$ adalah suatu graf lengkap maka untuk setiap dua titik sebarang di $K_{n}$ bertetangga. Jadi, diperoleh $d\left(v_{1}, w\right)=$ $d\left(v_{2}, w\right)$ untuk setiap $w \in V(G)-\left\{v_{1}, v_{2}\right\}$. Berdasarkan Lema 1 dapat disimpulkan bahwa

Dalam proses membentuk $\Pi$ sebagai suatu resolving partisi dari $K_{n}$, maka $v_{1}$ dan $v_{2}$ harus berada pada kelas-kelas yang berbeda dari $\Pi$. Karena $v_{1}$ dan $v_{2}$ adalah titik sebarang di $K_{n}$, maka untuk setiap titik yang ada di $K_{n}$ harus berada pada kelas yang berbeda dari $\Pi$. Dengan demikian, diperoleh $S_{1}=\left\{v_{1}\right\}, S_{2}=\left\{v_{2}\right\}, \ldots$, $S_{n}=\left\{v_{n}\right\}$ dimana $S_{1}, S_{2}, \ldots, S_{n}$ adalah kelaskelas partisi dari $\Pi$. Hal ini berarti $\Pi$ terdiri dari himpunan $n$-partisi, $\Pi=\left\{S_{1}, S_{2}, \ldots, S_{n}\right\}$ yang merupakan suatu resolving partisi dari $K_{n}$. Jadi, diperoleh bahwa $p d\left(K_{n}\right)=n$. Hal dapat juga dilihat berdasarkan Lema 1.

Untuk sebaliknya, misalkan $\mathrm{G}$ adalah graf terhubung berorde $n$, dan misalkan $\operatorname{pd}(G)=n \quad$ dimana $\quad V(G)=$ $\left\{v_{1}, v_{2} \ldots, v_{n}\right\}$ maka akan ditunjukkan $G=K_{n}$. Asumsikan $G \neq K_{n}$. Karena $G$ bukan merupakan suatu graf lengkap, maka dapat diasumsikan bahwa $d\left(v_{1}, v_{n-1}\right)=1$ dan $d\left(v_{n-1}, v_{n}\right)=2$. Sekarang perhatikan bahwa $\Pi=$ $\left\{S_{1}, S_{2}, \ldots \ldots, S_{n-1}\right\}$ menjadi himpunan partisi dari $V(G)$ dengan $S_{1}=\left(v_{1}, v_{n}\right)$ dan $S_{i}=\left\{v_{i}\right\}$ untuk $2 \leq i \leq n-1$. Jika dibuat representasi $v_{i}$ terhadap $\Pi$ dimana $1 \leq i \leq n-1$ maka diperoleh hanya entri ke $i$ dari $\mathrm{r}\left(v_{i} \mid \Pi\right)$ yang bernilai nol. Jadi, didapatkan representasi $v_{i}$ terhadap $\Pi$ yang berbeda untuk $1 \leq i \leq n-1$. Selain itu, diperoleh juga bahwa entri pertama dari $r\left(v_{n} \mid \Pi\right)$ adalah nol dan $\mathrm{r}\left(v_{n} \mid \Pi\right)$ berbeda dari seluruh $\mathrm{r}\left(v_{i} \mid \Pi\right)$ dimana $2 \leq i \leq n-1$. Diperoleh juga entri ke $(n-1)$ dari $\mathrm{r}\left(v_{n} \mid \Pi\right)$ adalah 2 serta entri ke $(n-1)$ dari $\mathrm{r}\left(v_{1} \mid \Pi\right)$ adalah 1. Hal ini menunjukkan bahwa $\mathrm{r}\left(v_{n} \mid \Pi\right) \neq$ $\mathrm{r}\left(v_{1} \mid \Pi\right)$. Dengan demikian, $\Pi$ adalah sebuah resolving partisi dari $G$ dengan batas atas dari $p d(G)$ adalah $n-1$. Jadi, $p d(G) \leq n-1$. Ditemukan sebuah kontradiksi.

\section{KESIMPULAN}

Berdasarkan hasil yang telah diperoleh pada pembahasan sebelumnya, dapat disimpulkan bahwa:

1. Suatu graf terhubung $G$ yang berorde $n$ memiliki beberapa bentuk resolving partisi dan $(\operatorname{dim}(G)+1)$ menjadi batas atas dari partisi dimensi graf tersebut. Jadi, diperoleh $P d(G) \leq \operatorname{dim}(G)+1$.

2. Misalkan $n$ adalah orde di suatu graf terhubung $G$, maka hanya terdapat tepat satu graf dengan $\operatorname{pd}(G)=n$, yaitu graf lengkap. Jadi, $\operatorname{pd}\left(K_{n}\right)=n$.

Setelah menulis artikel ini, penulis menyarankan untuk menelaah dimensi partisi dari bentuk graf lainnya karena masih banyak dari graf tersebut yang belum terungkap nilai dimensi partisinya.

\section{DAFTAR KEPUSTAKAAN}

Chartrand, G, \& Lesniak, L. (1979). Graph and Digraph. Kalifornia: A division of Wadsworf.Inc.

Chartrand, G, \& Oellermann, O. R. (1993). Applied And Algorithmic Graph Theory. USA: United States Copyright Act.

Chartrand, Gary, Raines, M., \& Zhang, P. (2000). The Directed Distance Dimension of Oriented Graphs. Mathematica Bohemica, 125(2), 155-168.

Chartrand, Gary, Salehi, E., \& Zhang, P. (2000). The partition dimension of a graph. Aequationes Mathematicae, 59(1-2), 4554. https://doi.org/10.1007/PL00000127

Chartrand, Gary, \& Zhang, P. (2001). The Forcing Dimension of a Graph. Mathematica Bohemica, 126(4), 711-720.

Javaid, I., \& Shokat, S. (2008). On the partition dimension of some wheel related graphs. Journal of Prime Research In, 4, 154-164.

Tomescu, I., \& Imran, M. (2009). On Metric and Partition Dimensions of Some Infinite Regular Graphs. Bulletin Mathématique de La Société Des Sciences Mathématiques de Roumanie, 52(4), 461-472. 